\title{
Direct Utilization of Naturally Occurring Sulfides for the Asymmetric Epoxidation of Aldehydes Mediated by Catalytic Ylides ${ }^{\dagger}$
}

\author{
Jacques Zanardi, Vincent Reboul, and Patrick Metzner ${ }^{\star}$ \\ Laboratoire de Chimie Moléculaire et Thio-organique (LMR CNRS 6507). ENSICAEN-Linersité de Caen. \\ 6 Boulevard du Maréchal Juin, 14050 Caen, France \\ Received Mav 18,2004
}

Key Words : Epoxidation. Sulfide. Biotin. Sulfonium ylide

Practical and economical aspects of asymmetric synthesis are receiving increased attention. ${ }^{1.5}$ Use of a catalytic amount of the enantioenriched ligand is now common in organometallic chemistry, but still remains a challenge for organocatalyzed reactions, in which the catalytic species is not centered on a metal aton. ${ }^{\circ}$

The availability of the chiral auxiliary ${ }^{7}$ is a critical parameter. A large variety of chiral auxiliaries have been prepared from the chiral pool ${ }^{\mathrm{s}}$ or by biotechnologies, through sequences which involve several steps. often in excess of 3 to 5 , leading to situations that are acceptable for preliminary exploration but defunitely less for large scale applications. ${ }^{9}$,

An ideal situation would be the use of a naturally occurring molecule directly as it is isolated. To our knowledge, there are not many molecules, which fulfill this expectation. They include:

- Tartaric acid for asymmetric Raney nickel hydrogenation. ${ }^{11}$

- Alkaloids. ${ }^{12}$ such as quinine or cinchonidine. for conjugate addition, ${ }^{13,14}[2+2]$ cycloaddition. ${ }^{15}$ sigmatropic rearrangement. ${ }^{16}$

- Aninoacids such as proline for aldolisation reaction. ${ }^{17}$

The scantiness of such molecules prompted us to explore natural chiral sulfides as auxiliaries for ylide mediated asynumetric epoxidation. We have been recently interested in achieving an enantioselective conversion of an aldehyde into an epoxide. mediated by a sulfonium ylide, and often referred as the Corey-Jolinson reaction. ${ }^{13}$ is This led us to design a $C$ : symmetric sulfide 1 , and to develop a catalytic sinple procedure. ${ }^{20.20}$ The chiral auxiliary was prepared from $(2 S, 5 S)$-hexanediol. which is accessible by enzymatic reduction $^{23,34}$ of 2.5 -hexanedione. and commercially avail- able. but not cheap

Other groups have also reported chiral sulfides for the efficient ylide epoxidation. Synthesis of the chiral sulfides required 3 to 5 synthetic steps from camphor, ${ }^{5-27}$ pulegone. ${ }^{28}$ mannitol, ${ }^{29}$ tartaric acid ${ }^{3 i j}$ or by an enzymatic reduction. ${ }^{31}$ or a resolution. ${ }^{32}$

Our present approach was of the utmost simplicity, i.e. screen natural chiral sulfides. preferably cyclic ones. This led us rapidly to two types of structures bearing a sulfur atom in a 5-membered ring. named penicillins 2 and biotin 3.<smiles>[R]C(=O)N[C@@H]1C(=O)N2[C@@H](C(=O)O)C(C)(C)S[C@H]12</smiles>

2

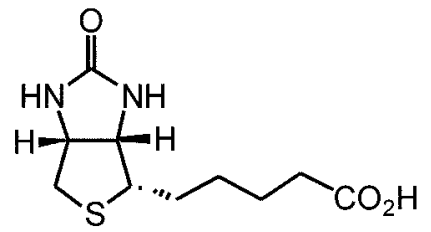

A variety of penicillins are available conmercially, as a result of the discovery of their outstanding antibiotic activity in 1929 by Fleming and their subsequent industrial production. We selected penicillin $\mathrm{G}(1, \mathrm{R}=\mathrm{Ph})$ for its availability and low cost. as well as the apparent lack of competing functional group for the key epoxidation step.

There are three critical parameters for stereocontrol. i) Formation of a single diastereomeric sulfonium salt. ii) Control of ylide conformation. iii) Facial selectivity of the ylide.

We expected first that the concave shape of penicillin 2 would direct the first step, reaction of benzyl bromide,

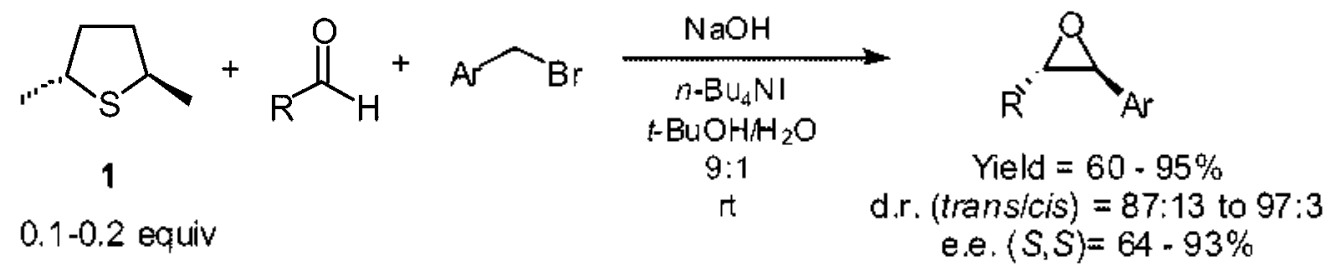

Scheme 1

\footnotetext{
Dedicated to Prof. Yong Hae Kim. for his comminitment to the synthetic organic chemistry of sulfur. superb achievements. and friendship all over the years.

${ }^{*}$ Corresponding Author. P. Metzner (metzneriäismra.fr)
} 


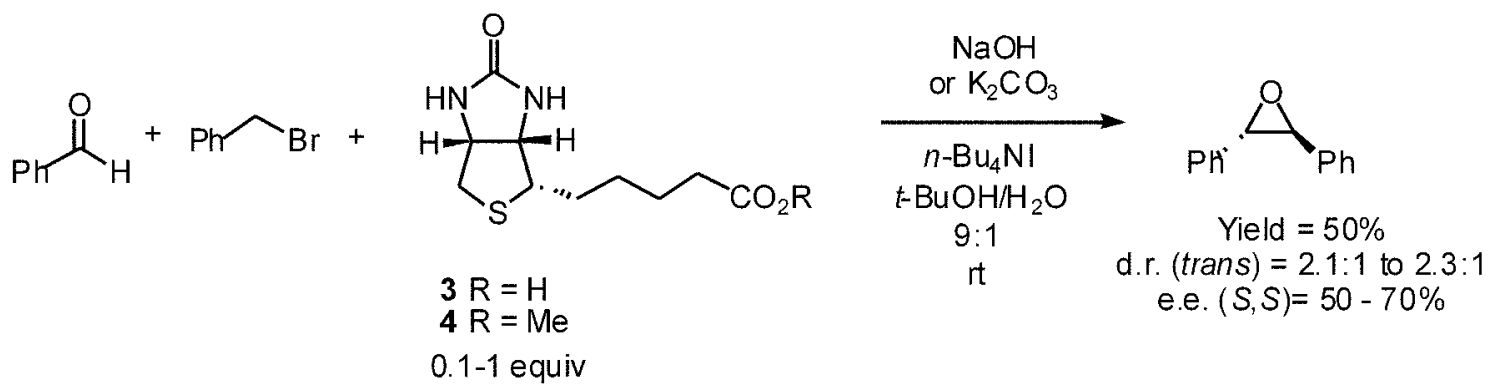

Scheme 2

towards a favored diastereomeric sulfonium salt. We anticipated that a privileged conformation of the awaited ylide would undergo attack of aldehyde on the face opposite to the hindered gem-dinethyl group. A computational study ${ }^{33}$ has led to demonstrate the feasibility of the thiazolidine nucleus for asymetric epoxidation.

\section{Results}

The reaction was tested with the one-pot procedure, which was successful with our $C_{2}$ synmmetric sulfide: use of a mixture of polar solvents. $t-\mathrm{BuOH}$ and $\mathrm{H}_{2} \mathrm{O}$, in a $9: 1$ ratio. and direct addition of stoichiometric penicillin $\mathrm{G} 2(\mathrm{R}=\mathrm{Ph})$ potassium salt ( 1 equiv), benzyl bromide ( 2 equiv). benzaldehyde ( 1 equiv). tetra- $/ 7$-butylammonium iodide (I equiv). and $\mathrm{NaOH}$ ( 2 equiv). Unfortunately, after a contact of one week at ambient temperature. no stilbene epoxide was detected. and the reagents were recovered. We noticed that the solubility of the penicillin was rather moderate in our solvent system. Subsequently, we performed the reaction in water. but no success was met either. We prepared the methyl carboxylate $^{34}$ and tested it in a variety of conditions. Unfortunately. still no epoxidation occurred. which may be due to the instability of the presumed sulfonium salt. ${ }^{35}$

We then investigated a second naturally occurring chiral sulfide. biotin $33^{36}$ It is an essential co-enzyme for carboxylation. a key step in gluconeogenesis and fatty acid biosynthesis. Isolated in 1936. characterized in 1942. it is now produced industrially by synthesis for therapeutic uses and food addition to stock feeding.

In line with our purpose. it bears a thiolane ring with a stereogenic center. adjacent to the sulfur atom and bearing a 5 -carbon carboxylic acid chain. potentially providing steric hindrance.

Right at the first test of epoxidation. we observed interesting results. The reaction was conducted under our standard one-pot conditions. first with a stoichiometric amount. After a period of one day. a $50 \%$ yield of stilbene oxirane was isolated. Indeed biotin mediated the sulfur ylide reaction. with an enantiomeric excess of $50 \%$ in favor of the $(S, S)$ enantiomer. A modest selectivity for the trans diastereomer was observed.

We attempted a catalytic use $e^{22.37-39}$ of biotin. With 0.1 equivalent. a reasonably low loading for organocatalysis. 5.39 we were glad that the reaction worked. with results similar to
Table 1

\begin{tabular}{|c|c|c|c|c|c|c|c|}
\hline Entry & Sulfide & Amount & Base & $\begin{array}{l}\text { Time } \\
\text { (d) }\end{array}$ & $\begin{array}{l}\text { Yield } \\
(\%)\end{array}$ & $\begin{array}{c}\text { d.r. } \\
\text { trans/cis }\end{array}$ & $\begin{array}{l}\text { e.e. } \\
(\%) \\
(S S)\end{array}$ \\
\hline 1 & Penicillin $G$ & l & $\mathrm{NaOH}$ & 7 & 0 & & \\
\hline 2 & $\begin{array}{c}\text { Methyl ester } \\
\text { of penicillin } \\
G\end{array}$ & 1 & $\mathrm{~K}_{2} \mathrm{CO}_{3}$ & 7 & 0 & & \\
\hline 3 & (+)-Biotin & 1 & $\mathrm{NaOH}$ & 1 & 50 & $67: 33$ & 50 \\
\hline 4 & & 0,1 & $\mathrm{NaOH}$ & 6 & 50 & $69: 31$ & 53 \\
\hline 5 & Methyl ester & 0,1 & $\mathrm{~K}_{2} \mathrm{CO}_{3}$ & 7 & 50 & $70: 30$ & 70 \\
\hline
\end{tabular}

"Analyzed from the NMR spectrum of the crude material. "Enantiomeric excess measured by HPLC using Daicel Chiralpak AD column.

the stoichiometric series. We noted that biotin is not much soluble in water. and less so in alcohols. Therefore, our reaction conditions might not provide optimum reaction conditions.

The reaction was performed in $\mathrm{H}_{2} \mathrm{O}$, instead of a mixture of $t-\mathrm{BuOH} / \mathrm{H}_{2} \mathrm{O}$. but this did not give any improvement. The very same yield and selectivities were observed.

We decided to improve the solubility of the chiral auxiliary, under our reaction conditions. by fonming the methyl ester of biotin. At the epoxidation stage. it required the use of a non-hydrolytic base. and we selected potassium carbonate. ${ }^{21}$ The reaction was nun with a loading of 0.1 equiv of biotin ester. After a week. stilbene oxide was isolated in a $50 \%$ yield a diastereomeric ratio of $7: 3$, and the higher enantiomeric excess that we have met in this series. $70 \%$ $(S, S)$.

\section{Discussion}

Our initial challenge has been successful. Direct utilization of a naturally occurring cyclic sulfide. biotin. readily available. is feasible for ylide-mediated epoxidation of aldehydes.

Simple experimental conditions involved mere addition of the reagents. $10 \%$ equivalent of biotin. and stirring the onepot reaction mixture at room temperature for 6 days. The yields and e.e.'s are not reaching the present standards for general applicability. but they nicely illustrate our simple principle.

To explain the predominant formation of the $(S, S)$ enantiomer. we propose ${ }^{\text {?t }}$ the model depicted on Scheme 3. The 


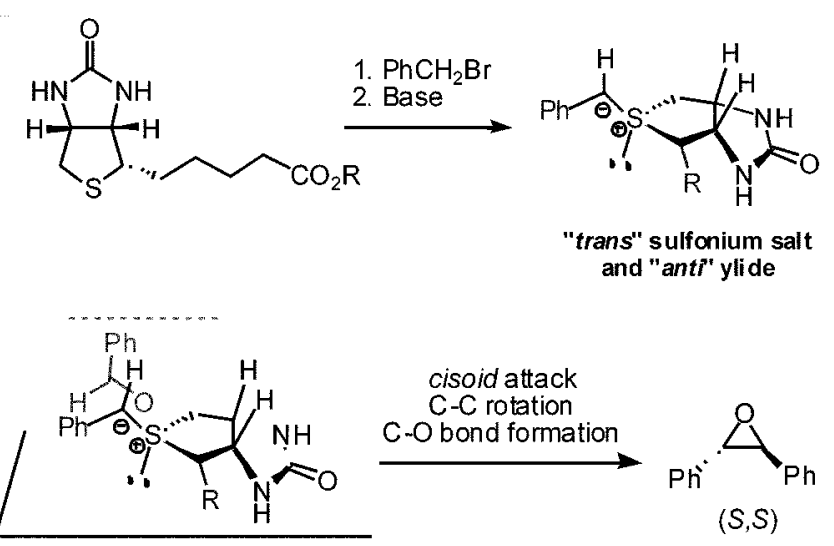

Scheme 3

alkylation of the sulfur atom would take place preferentially with the lone pair located trans to the carboxylic chain, but we believe that this might not be entirely selective and thus erode the enantiomeric excess, a situation which was avoided with our previous $C_{2}$ symmetric thiolane. By subsequent deprotonation of the sulfonium salt, an anti ylide could be preferred. locating the sulfur lone pair in the same plane as the $\mathrm{H}$ and $\mathrm{Ph}$ groups on the ylidic carbon $(\mathrm{H}$ and lone pair $(a n t i)$. The approach of the aldehyde would take place backward ( $s i$ face of the ylide). to avoid steric compression with the carboxylic chain. $\alpha$ to the sulfonium center.

In terms of enantiomeric excess, the higher induction was observed with a simple derivative of biotin, its methyl ester. which led to $70 \%$ e.e.

The diastereoselectivity is modest $(67: 33-70: 30)$ in favor of the trans isomer. It brings some information about a stereocontrol. which is not yet fully understood. Whereas the groups of Aggarwal ${ }^{3 \leqslant 19}$ and Cavallo-Solladie ${ }^{210}$ observed a marked selectivity in favor of the trans stilbene oxirane, we have met several differences. which we tend to believe are related to the structural features of the sulfide. With moderately hindered sulfides or with aromatic substituents on the sulfur atom. we have observed trans cis ratios from $90: 10$ to $60: 40$. Though. in most cases. we do not have experimental evidence (except for ferrocenyl sulfides ${ }^{41}$ ), we propose a marked kinetic control compatible with the model proposed by Aggarwal. ${ }^{43.43}$ With moderately hindered sulfides. the formation of the $<s, n>$ betaine is less reversible (easier C-C bond rotation) than with hindered sulfides and thus leads to more $c i s$ oxirane

\section{Conclusion}

We have shown that it is feasible to use a sulfide directly from the $<<$ supplier $\gg$. mother's nature. to mediate conversion of aldehydes into oxiranes in a non-racemic fashion through sulfur ylides. It can be added to the very short list of natural molecules. which are directly utilized for așymmetric chemical synthesis.

\section{Experimental Part}

Typical procedure. To a solution of (+)-biotin (24 mg. $0.05 \mathrm{mmol}$. 0.1 eq.) in $1 \mathrm{~mL}$ of a mixture of $t-\mathrm{BuOH} / \mathrm{H}_{2} \mathrm{O}$ 9/1 were added benzyl bromide ( $120 \mu \mathrm{L}$. $1 \mathrm{mmol} .2 \mathrm{eq}$ ), powdered $\mathrm{NaOH}$ (40 $\mathrm{mg}, \mathrm{l}$ mmol. 2 eq.). n-tetrabutylammonium iodide (185 $\mathrm{mg}, 0.5 \mathrm{mmol}$, I eq.) and benzaldeliyde (53 $\mathrm{mg}$. $0.5 \mathrm{mmol}$. I eq.). The reaction mixture was stirred at room temperature for 6 days. The reaction was judged complete by thin layer chromatography (TLC). TLC plates were visualized by UV light and by treatment with a solution of 2.4-DNPH $(400 \mathrm{mg}$ in $100 \mathrm{~mL}$ of $\mathrm{HCl} 1 \mathrm{~N}$ ). Water $(5 \mathrm{~mL})$ was added. The aqueous phase was extracted with diethyl ether ( $10 \mathrm{~mL}$. 3 times); the combined organic layers were dried over $\mathrm{MgSO}_{4}$, and then concentrated to dryness. The crude product was submitted to column chromatography (silica gel. 98/2 petroleum ether/dietlyyl ether) to afford the stilbene oxide (49 mg. $0.25 \mathrm{mmol} .50 \%$ yield. d.r.: $2.2: 1$. HPLC analy sis was performed on a Daicel Chiralpak AD column with a $9: 1$ hexane isopropanol eluent mixture at a flow of $1 \mathrm{~mL} / \mathrm{min}$ : e.e. $=50 \%$.

Acknowledgment. We are grateful for the financial support of the "Ministère de la Recherche et des Nouvelles Teclunologies" (scholarship to Jacques Zanardi and equipment). CNRS (Centre National de la Recherche Scientifique), the "Région Basse-Nonnandie" and the European Union (FEDER funding).

\section{References}

1. Collins. A. N.: Sheldrake. G. N.: Crosby. J. Chirality in Industry - Developntents in the Commercial lamufactare and Applications of Optically Active Componds: Wiley: Chichester. 1997.

2. Tye, H. Comina. P. J. J. Chem. Soc. Perkin Troms. $12001,1729$. 1747.

3. Blaser. H.-U. Chem Commun. 2003. 293-296.

4. Breuer. M.: Ditrich. K.: Habicher. T.: Hauer. B.: Kesseler. M.: Stürmer. R.: Zelinski. T. Angew. Chent. Int Ed 2004. +3. 788-824.

5. Blaser. H. U; Schmidt. E. Astnmetric Catalvsis on Industrial Scale: Challenges, Approaches and Solutions; Wilev-VCH: Weinheim, 2004.

6. Dalko. P. I.: Moisant. L. Angew: Chem. Int. Ed. 2001. 40. $3726-$ 3748 .

7. Hermann. R. Stereaselective Sinthesis (Houben-Wenil): Helmchen. G:: Hoffinann, R. W.: Mulzer, J:; Schaumann. E., Eds:; Georg Thieme: Stuttgart, 1996; Vol. E21, pp 5759-6001.

8. Blaser. H.-U. Chem Rev 1992, $92.935-952$.

9. Kotha. S. Tetrahedron 1994. 50.3639-3662.

10. Sheldon. R. A. Chiwotecholog, Industrial Synthesis of Optically Active Contpounds: Marcel Dekker: New York. 1993: pp 143171 .

11. Sugimura. T.: Nakagawa. S.: Tai. A. Bull. Chent Soc. Jpn 2002. $75.355-363$

12. Wynberg. H. Top. Stewochem. 1986. 16. 87-129.

13. Hermannl. K.: Wynberg. H. J. Ong Chem 1979. ft. 2238-2244

14. Hiemstra. H.: Wynberg. H. $J$. Am. Chent Soc. 1981. 103.417-430.

15. Wynberg. H.: Staring, E. G. J. J. Am. Chem. Soc. 1982. J04, 166168 .

16. Kazmaier. U.: Krebs. A. Angew: Chem. Int Ed. 1998, 34. 20122014. 
17. Hajos Z. G.: Parrish. D. R. J. Org. Chem 1974. 39.87-129.

18. Li. A.-H.: Dai. L.-X.: Agganval. V. K. Chem. Rev 1997. 97.23412372.

19. Agganial. V. K.: Richardson. J. Chent. Commin. 2003. 26442651 .

20. Iulienne. K: Metzner, P.: Henryon. V: Gremer A. J. Org Chem. $1998,63,4532-4534$

21. Julienne. K.: Metzner. P.: Henryon. V. J. Chem. Soc. Perkin Trans. $11999.731-736$.

22. Zanardi. J.: Leriverend. C.: Aubert. D.: Julienne. K.: Metzner. P. J. Org. Chem. 2001. 66. 5620-5623.

23. Lieser J. K. Symth. Conmm. 1983. 13. $765-767$.

24. Haberland. J.: Hummel, W: Daussmann, T.: Liese. A. Org. Proc. Res. De?: 2002. sous presse.

25. Agganial. V. K.: Alonso. E.: Hynd. G.: Lydon. K. M.: Palmer. M. J.: Porcelloni. M.: Studley, J. R. Angew: Chem. Int Ed 2001. to. 1430-1433.

26. Saito, T.: Akiba, D.: Sakairi. M.: Kanazawa. S. Tetrahedron Lett. $2001+2,57-59$.

27. Li. A.-H.: Dai. L.-X.: Hou. X.-L.: Huang. Y.-Z.: Li. F.-W. J. Org. Chem. 1996.61. $489-493$

28. Solladie-Cavallo. A.: Diep-Vohuule. A. J. Org. Chem. 1995.60. $3494-3498$

29. Winn, C. L.: Bellenie. B. R.: Goodman, J. M. Tetrathedron Lett. 2002, $43,5427-5430$.
30. Ishizaki, M.: Hoshino. O. Heterocycles 2002, 57. 1399-1402.

31. Hayakawa. R.: Shimizu. M. Symlett 1999. 1328-1330.

32. Miyake. Y: Oyamada. A.: Nishibayashi. Y: Uemura. S. Heteroaton Chent. 2002. 13. 270-275

33. Myllymäki. V. T.; Lindvall, M. K.; Koskinen, A. M. P. Tetrahedron 2001. 57, 4629-4635.

34. Bell. M. R. Carlson, J. A.; Oesterlin. R. J. Org. Chem. 1972, 37. 2733-2735

35. Denerley. P. M.: Thomas. E. J. J. Chem. Soc., Perkm Trons. I 1979.3175-3189.

36. De Clerce. P. J. Chent. Rey: 1997. 97, 1755-1792.

37. Aggarwal, V. K. Symlett 1998. 329-336.

38. Aggarwal, V. K. Comprehensive Asymmetric Catalysis, Jacobsen. E.: Pfaltz. A.: Yamamoto. H.. Eds.: Springer: Berlin. 1999: Vol. 2. pp 679-693.

39. Aggarwal. V. K.: Wint1. C. L. Acc. Chent Res. 2004. in the press.

40. Solladié-Cavallo, A.; Diep-Vohuule. A.; Sunjic. V: Vunkovic. V. Tetrahedron: Asymmety 1996. 7, 1783-1788.

41. Minière. S.: Reboul. V.: Arrayás. R. G.: Metzner. P.: Carretero. J. C. Simthesis 2003. 2249-2254.

42. Aggarwal. V. K.: Calamai. S.: Ford. G. I. J. Chem. Soc. Perkin Trans. ] 1997, 593-599.

43. Aggarwal, V. K, Harvey, J. N.: Richardson. J. J. Am. Chem. Soc. 2002. $12+, 5747-5756$ 